\title{
Bun Nerrolegy oenen Functional neurological disorders: effective teaching for health professionals
}

\author{
Alexander Lehn, ${ }^{1,2}$ Dharsha Navaratnam, ${ }^{3}$ Megan Broughton, ${ }^{4}$ Vince Cheah, ${ }^{5}$ \\ Alison Fenton, ${ }^{3}$ Karl Harm, ${ }^{3}$ Diana Owen, ${ }^{6}$ Paul Pun ${ }^{7}$
}

To cite: Lehn A, Navaratnam D, Broughton M, et al. Functional neurological disorders: effective teaching for health professionals. BMJ Neurology Open 2020;2:e000065. doi:10.1136/ bmjno-2020-000065

- Additional material is published online only. To view please visit the journal online (http://dx.doi.org/10.1136/ bmjno-2020-000065).

Received 19 April 2020 Revised 23 May 2020 Accepted 02 June 2020
Check for updates

(C) Author(s) (or their employer(s)) 2020. Re-use permitted under CC BY-NC. No commercial re-use. See rights and permissions. Published by BMJ.

For numbered affiliations see end of article.

Correspondence to

Dr Alexander Lehn;

a.lehn@uq.edu.au

\section{ABSTRACT}

Objectives To provide an outline for the delivery of an educational course or lecture about functional neurological disorders (FND) that is directed towards health professionals with varying clinical knowledge and to highlight the educational efficacy that can be derived from a well-designed educational platform.

Method Through multidisciplinary collaboration, a course designed to develop the skills for diagnosis and management of FND was created. Elements essential to the delivery of education are: (A) knowledge creation; $(B)$ facilitating multidisciplinary cross-pollination; (C) listening to patients' experiences; (D) communication skills practice; (E) case studies; (F) discipline specific mentoring; (G) establishing and addressing participant learning goals and (H) developing collegial and referral networks. Changes in participants' knowledge and clinical practice were assessed via anonymous questionnaires before and after the course.

Results Dramatically improved knowledge and confidence in assessment and management of people with FND has been found both immediately following the course as well as on 6-month follow-up.

Conclusion It is possible to make real change in the understanding and management of medical and allied health clinicians working with people with FND with a low-cost intervention. Also, the development of educational networks and multidisciplinary collaboration can lead to the creation of therapeutic platforms for the diagnosis, management and advocacy of this patient group.

\section{INTRODUCTION}

Patients with functional disorders are commonly seen in medical practice. In neurology outpatient clinics, patients with functional neurological disorders (FND) are the second most common presentation after headaches. ${ }^{1}$ Interest in this field among health professionals is clearly rising, reflected by an increasing number of publications and conference sessions covering FND. While this is encouraging, most health professionals still have outdated views about FND and even those with an interest in the area often struggle with management and treatment. ${ }^{2}$ Changing clinical practice often requires experiential learning; however, obtaining this practical training can be difficult due to the complexities of this patient group. In this article, we will share our experience of delivering a multidisciplinary 'FND Masterclass'. We will outline the rationale behind how the Masterclass was set up using a cohesive interprofessional team-based approach. We will also highlight helpful features of the FND Masterclass and how they can be adapted for other teaching settings and guide readers to helpful resources to aid the development of education material.

\section{METHODS}

The FND Masterclass targets specialists, trainees, medical and allied health professionals with interest in FND. It is delivered biannually over 2 days face to face to small groups of health professionals by experts in multidisciplinary management of patients suffering from FNDs (including a neurologist, psychiatrists, psychologists, physiotherapists and a clinical nurse.

\section{The educational framework}

In the FND Masterclass, we aim to set up participants for successful practical application of difficult conversations by covering common communication pitfalls, plus management of FND by each of the five members of the multidisciplinary team at the commencement of the workshop.

The core of the FND Masterclass is simulation-based training in a psychologically safe environment for participants. Simulation and subsequent sensitive debriefing enable learners to experience potentially challenging clinical situations without patient harm and reflect on how they could apply their insights into practice. ${ }^{34}$ Clinicians may become defensive, intimidated or feel their professional identity threatened during simulation. ${ }^{4}$ This is mitigated by having small interprofessional 
groups, establishing a confidentiality contract, acknowledging the task is difficult even for experienced clinicians and setting realistic expectations and learner-centred goals.

The simulation is based on a plausible scenario that was developed and reviewed by the multiprofessional team and a simulation educator. It is supported with realistic resources such as an ED discharge letter, MRI scans and a telehealth referral. Credible standardised patients provide a high experiential fidelity, ${ }^{3}$ and our patient actors have been trained to mobilise, behave and respond authentically. They can also increase the complexity of their behaviour if participants have requested a more challenging patient interaction.

Prior to the simulation, the groups brainstorm possible strategies for engaging the patient. Each participant then has an opportunity to interact with the simulated patient, and their consultation is then debriefed by a trained faculty member in a respectful, constructive manner. There is emerging evidence that self-debriefing and peer-led debriefing can enhance learning, ${ }^{5}$ so participant observers and patient actors are invited to provide input. Discussion focuses on techniques that were effective and what the group collectively can learn to enhance future patient interactions.

While it might be difficult to replicate this simulationbased approach, there are several instructional methods from the Masterclass that can be used for teaching to enhance learning and confidence in managing FND patients in other settings. We will outline key features of the these and include suggestions and resources for the development of FND teaching:

\section{1: Updating knowledge bases/knowledge creation}

In most instances, the first part of any FND tutorial would be done in a didactic format with the aim of updating participants on current concepts and evidence-based practice. In an area like FND, there are often health professionals in the audience with a broad diversity of baseline knowledge, and it is important to ensure there is mutual understanding. For the introductory lectures in the Masterclass, we therefore address terminology, common misconceptions about FND, principles of diagnosing FND and how to confidently diagnose based on positive clinical signs.

Resources: an excellent and comprehensive resource for all aspects of FNDs (from history and epidemiology to current treatment approaches) is the Handbook of Clinical Neurology on FND by Hallett et al. ${ }^{6}$ Espay and colleagues recently published a helpful article summarising 'Current Concepts in Diagnosis and Treatment of Functional Neurological Disorders', ${ }^{7}$ which also contains pictures to explain some of the more commonly seen clinical signs in patients with FND. Currently, there is little published literature about assessment and treatment of FND in children and adolescents, but Kozlowska ${ }^{8}$ and her team have a book in press, which covers neurobiological concepts as well as treatment approaches in this group. We use videos from our patients to highlight positive 'rule in' signs, but for presenters who do not have their own videos available, there are a number of online resources and articles that have videos that can be used, for example:

- www.neurosymptoms.org: has videos of functional tremors, Hoover's sign and patients with dissociative attacks.

- Review article by Stone and Carson ${ }^{9}$ as part of the Continuum series that has a number of supplemental videos highlighting typical positive clinical features on examination.

- fndaustralia.com.au: short explanation videos aimed at non-professionals to explain basic aspects of diagnosis and treatment of FND (https://fndaustralia. com.au/resources/educational-videos.html).

- A more detailed overview (including sensitivities and specificities) of various positive clinical signs has been published by Garcin $^{10}$ in 2018.

\section{2: Enabling good teamwork and cross-pollination}

In our opinion, there are two aspects of multidisciplinary treatment of FND that have a particularly large impact on outcomes: one is consistent language across the whole treating team (down to the exact terminology used) and another is team member's sound knowledge about the other team member's roles and approaches. This allows the referring doctor to effectively facilitate a referral and manage patient expectations. Such an approach is particularly important when referring patients to psychiatry or psychology for treatment given the stigma and reluctance to seeing mental health professionals that still often exist. There is consistent evidence of higher rates of mental health conditions such as depression, anxiety and trauma in patients with FND, and for many, these issues need to be addressed for optimal treatment of functional symptoms. ${ }^{11}$ Moreover, there is growing evidence of the effectiveness of psychological treatments, such as cognitive-behavioural therapy, for treating functional symptoms themselves. ${ }^{12} 13$ In the sections 'Psychiatric treatment of FND: case studies', 'psychological therapy for non-psychologists' and 'physiotherapy for non-physiotherapists' of the Masterclass, all health professionals involved in the care of FND patients can learn about what is involved in treatment (ie, the approach and basic strategies used). This understanding connects health professionals, gives them more confidence when referring and can also help them to reinforce strategies the patient was taught by other therapists (such as pacing or grounding techniques).

\section{Resources:}

- What should we say to patients with symptoms unexplained by disease? The 'number needed to offend ${ }^{14}$ : this article from 2002 discusses various labels used for symptoms unexplained by disease and provides the rationale for the use of the term functional neurological disorder.

- Nielsen et al published consensus recommendations regarding physiotherapy for functional motor disorders (including an explanation about the rationale 
for physiotherapy as part of a multidisciplinary treatment). The shorter version of the article can be used as a starting point for non-physiotherapists. The longer version gives more comprehensive advice and contains more examples of ways to discuss certain scenarios and also case examples. ${ }^{15}$ Gray $e t a l^{16}$ have an article in press that describes treatment approaches for functional movement disorders in children and adolescents.

- Our team published a functional neurological disorder learning guide. This guide can be helpful for any health professional involved in FND to assist in explaining each team member's role as well as the rationale behind the use of certain terminology. The learning guide can be downloaded for free from fndaustralia.com.au (https://fndaustralia.com.au/ resources/clinical-tools.html).

\section{3: Understanding why it is so important to get it right}

For our FND Masterclasses, we always invite a patient to share their story. We feel this is invaluable and reminds us of the importance of further developing our skills and practice.

Resources: having an actual patient speaking might not be possible for a lecture or tutorial, but sharing a reallife patient story is still beneficial. Patient testimonials can be found on patient support websites like fndhope.

I am confident in understanding Functional Neurological Disorders' pathogenesis, underlying mechanisms and treatment strategies.

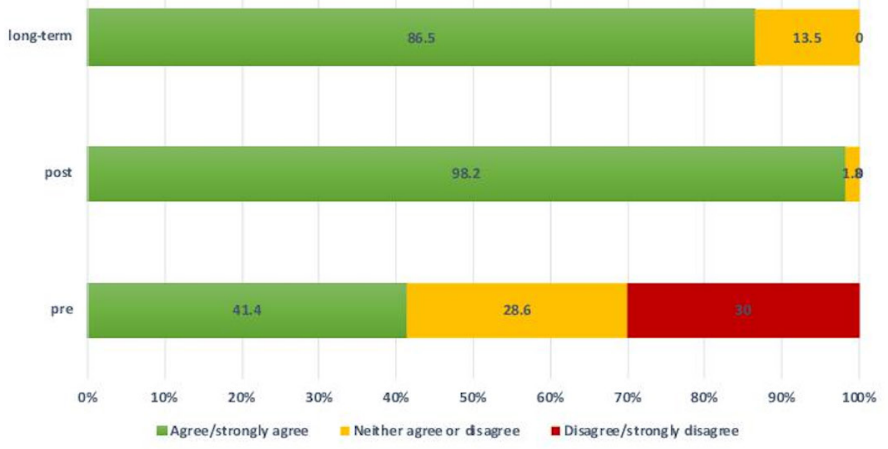

I am confident discussing the possibility of a Functional Neurological Disorder with a patient, and still being able to maintain an effective relationship with them.

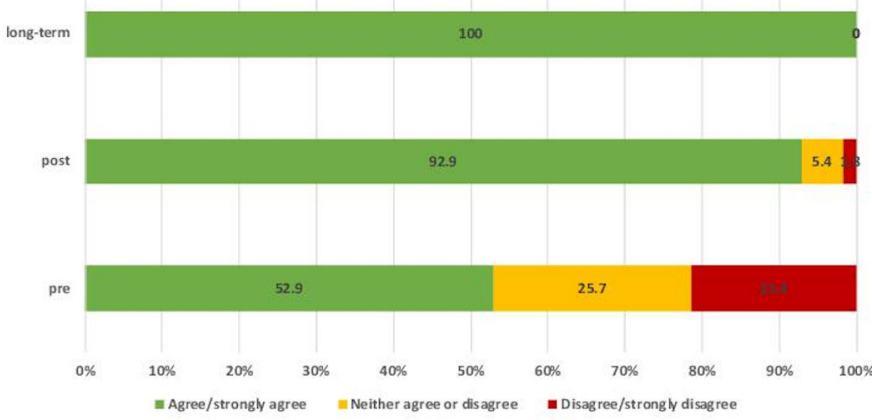

org (https://fndhope.org/living-fnd/patient/), fndaus. org.au or www.neurosymptoms.org. fndhope.org also has large library of FND-related videos here: https:// fndhope.org/resources/fnd-videos/. An introductory film about the diagnosis and treatment of FND (including many patient stories) can be found on YouTube: https:// www.youtube.com/watch?v=w4lqr4Mo32M.

\section{4: Putting it into practice}

As mentioned above, the core of the FND Masterclass is simulation-based teaching sessions. Although this is the part of the workshop that people are most apprehensive about, it is also the part participants find the most helpful.

Again, this might not be feasible in a lecture setting, but practising communication skills can still be possible. On some occasions at other education events, we have demonstrated communication strategies by role modelling some scenarios in front of large audiences ourselves. While this still has participants in a passive rather active learner role, it helped us to emphasise several key points.

Resources: we have previously published a photo story about ways to explain the diagnosis of FND (and how to avoid common pitfalls), ${ }^{17}$ which can be used as a basis for teaching. There are similar articles by other authors for practical advice regarding approaches to explanation in FND in general or more specifically regarding

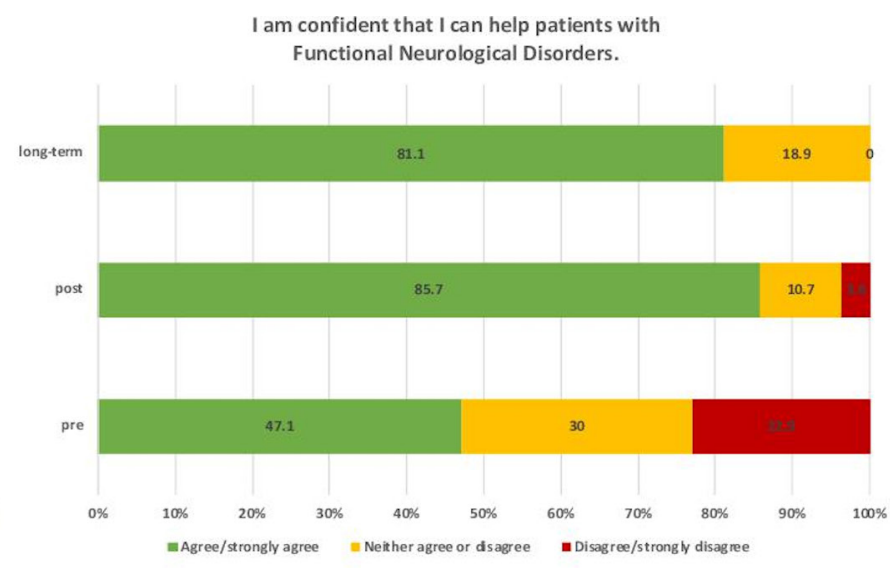

I am confident in recognising positive clinical signs of Functional Neurological Disorders.

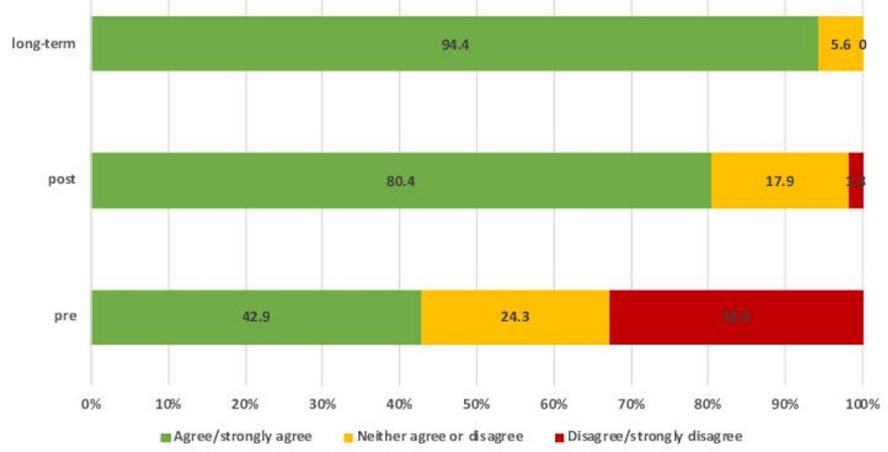

Figure 1 Responses to key questions regarding management of FND. FND, functional neurological disorder. 
Table 1 Selected quotations from FND Masterclass participants

\section{Healthcare professional Selected quotations}

Component of the FND Masterclass participants found most useful

Hearing from patients - why it is Neurology trainee important to get it right

Nurse

Practice skills

Physiotherapist

Psychologist

\section{Changes participants made in their work practic
Diagnosis and communication Physiotherapist}

with patients

Neurology trainee

Changing clinical practice and Neurology trainee

continuing education

Psychologist

Speech pathologist

Nurse

Psychiatrist
'Listening to a first hand account from a former FND sufferer'.

'Meeting [the patient telling her story] first hand. Seeing and hearing directly the impact of FND and the outcomes of interventions have'.

'Clinical simulations with actors. It's not only helpful practicing the language but learning strategies from others in the group and the actors perspectives'.

'Role plays and examples on ways to explain the diagnosis in a clear and supportive way. I love the software analogy!' the approach to communicating the diagnosis of dissociative attacks. ${ }^{18} 19$

\section{5: Learning from cases}

Learning from actual case examples can be more constructive than didactic teaching. ${ }^{20}$ Throughout our course, we navigate through specific case examples in depth, highlighting the role of various disciplines. A key teaching and discussion point is how to deliver effective multidisciplinary therapy within existing resources. Issues explored in this session include overcoming local barriers and working in challenging settings, for example, managing FND patients without input from a neurologist or without access to other health professionals for multidisciplinary management. Other common concerns that we discuss are, for example, what to do when patients do not accept the diagnosis of FND or are not progressing (or even worsening) during treatment.

Resources:

There are several helpful resources that can be used for case examples:

- The long version of consensus recommendations published by Nielsen $e t a l^{15}$ in 2015 contains a section about many of these frequently asked questions and
'I am taking more time to explain to the patient what is going on with their condition'. 'Improved confidence in diagnosing FND'.

'In the next year, I will become a neurology consultant \& will focus on continuity of care \& goal setting plus setting up a FND network locally to help me manage my patients'.

'l'd like to continue to talk with other clinicians with an interest in this area to continue to enhance my knowledge and understanding of tx approaches'.

'I have more confidence setting goals and implementing treatment for people I think have FND'.

'I'm more likely to communicate with patients instead of handballing onto another colleague'.

'Provision of education to other health providers including GPS, psychiatry registrars and psychiatrists'. also details instructive cases to demonstrate how their recommendations can be put into practice.

- Stone et al published two selections of case studies to highlight the principles of diagnosis and treatment of functional limb weakness, dissociative attacks and other functional symptoms. ${ }^{21} 22$

\section{7: The car park}

We start every Masterclass with an interactive session where we build a 'car park' of questions participants would like to have answered. This is built on throughout the course. Towards the end of the Masterclass, we discuss all the remaining questions with all participants (or address them during the in-depth teaching sessions if they are too specialised for a wider audience). Common issues covered here have included driving restrictions for FND and how to approach requests for disability support. The main reason to use this 'car park' technique is that some participants may not feel comfortable asking certain questions in the presence of others and so have the chance to add their questions between sessions. It also helps to maintain the flow of the teaching course as a participant may ask a question that you know will be addressed more completely in an upcoming section of 
the training. The idea behind this is to completely 'drain' any unanswered questions and to ensure that every issue participants struggle with (but may be reluctant to raise) has been addressed.

\section{8: Developing a network}

A major barrier that holds health professionals back from being more proactive in the care of FND patients is the lack of a functioning network around them: although many doctors might be happy to see patients with FND they are often unsure who to refer to for therapy. Another issue is that while many psychologists and allied health professionals are interested in this patient group, they feel that patients are often just 'dumped' on them without a diagnosis. ${ }^{2}$ Using the Masterclasses as a steppingstone, we have built up a network of health professionals across Australia with interest in FND in order to bridge these gaps (fndaustralia.com.au). We believe that running lectures and tutorials about FND can be a platform to connect like-minded people and build up clinical networks.

\section{RESULTS}

\section{Can we help health professionals change their clinical practice?}

We wanted to explore whether our teaching approach is helpful, and if this knowledge translates to change of management longer term. Consequently, we surveyed participants before and after our Masterclasses via anonymous questionnaires for feedback and to better understand challenges in clinical practice (asking questions like: 'How confident are you in discussing the possibility of a Functional Neurological Disorder with a patient and still being able to maintain an effective relationship with your patient?', see online supplementary document). Participants were also invited to participate in another anonymous online survey via email 6 months after attending the teaching course to assess longer-term changes. A total of 70 health professionals participated in the survey immediately before and after the Masterclass (2 neurology trainees, 6 neurologists, 5 psychiatrists, 3 rehabilitation physicians, 12 psychologists, 4 general practitioners, 26 physiotherapists and 12 others). Of these, 37 (53\%) also participated in the long-term follow-up. Figure 1 summarises responses to four of the key questions asked. Marked improvements in reported skills and confidence where seen immediately after the FND Masterclasses and they were maintained (and often improved further) at longer term follow-up. At the 6-month follow-up participants were also asked to comment on the component of the FND Masterclass they found most useful and on the changes they have made in their work practice since attending the Masterclass (see table 1 for selected quotations).

Many participants commented on how helpful it was to practice examination skills and patient communication with actors in a safe environment. Another frequent remark was on the impact it had to hear a patient's story directly from the patient and being able to ask him or her about their experiences.

\section{DISCUSSION}

In the medical community, there is clearly an interest in improving understanding and treatment for patients with FND. In order to acquire skills and change practice, new teaching approaches rather than purely didactic teaching methods are required. Although effective communication is acknowledged to be an essential skill to provide optimal patient outcomes, clinicians report feeling undertrained and unprepared for challenging conversations. ${ }^{3} 2324$ Simulation-based training has been shown to improve communication skills in challenging clinical interactions. ${ }^{32324}$ It is encouraging to see the degree of change in health professionals' opinion and practice that can be achieved through short, practical and low-cost multidisciplinary teaching courses. However, even with limited time and resources for an education session, simple strategies for teaching and collaboration can enhance engagement and learning. Better patient outcomes and higher satisfaction among health professionals treating patients with FND will be achieved by including education on underlying mechanisms of FND and evidence-based treatment approaches in medical school teaching, as well as in the training of other health professionals.

\section{Author affiliations}

${ }^{1}$ Department of Neurology, Princess Alexandra Hospital, Woolloongabba, Queensland, Australia

${ }^{2}$ The University of Queensland Princess Alexandra Hospital Clinical School, Woolloongabba, Queensland, Australia

${ }^{3}$ Active Rehabilitation, Brisbane, Queensland, Australia

${ }^{4}$ Brisbane Clinical Neuroscience Centre, Brisbane, Queensland, Australia

${ }^{5}$ Queen Elizabeth II Jubilee Hospital, Brisbane, Queensland, Australia

${ }^{6}$ Mater Education Centre, Brisbane, Queensland, Australia

${ }^{7}$ Emotional Health Unit, Mater Misericordiae Health Services Brisbane Ltd, Brisbane, Queensland, Australia

Acknowledgements The authors would like to thank Dr. Rian Dob, Alex Downie, Dr. Nicola Warren and the Mater Education team for their help with the development and their ongoing support with running the FND Masterclasses.

Contributors AL: analysed the data, and conception and drafting of manuscript. DN and MB: conception and drafting of manuscript. VC, AF, KH and PP: revised the manuscript for intellectual content. DO: major role in the acquisition of data and revised the manuscript for intellectual content.

Funding The authors have not declared a specific grant for this research from any funding agency in the public, commercial or not-for-profit sectors.

Competing interests None declared.

Patient consent for publication Not required.

Ethics approval This project received exemption from ethical review from the local human research ethics committee (reference EXMT/MML/58491 (V1)).

Provenance and peer review Not commissioned; externally peer reviewed. Data availability statement Data are available on reasonable request.

Open access This is an open access article distributed in accordance with the Creative Commons Attribution Non Commercial (CC BY-NC 4.0) license, which permits others to distribute, remix, adapt, build upon this work non-commercially, and license their derivative works on different terms, provided the original work is 
properly cited, appropriate credit is given, any changes made indicated, and the use is non-commercial. See: http://creativecommons.org/licenses/by-nc/4.0/.

\section{REFERENCES}

1 Stone J, Carson A, Duncan R, et al. Symptoms 'unexplained by organic disease' in 1144 new neurology out-patients: how often does the diagnosis change at follow-up? Brain 2009;132:2878-88.

2 Lehn A, Bullock-Saxton J, Newcombe P, et al. Survey of the perceptions of health practitioners regarding functional neurological disorders in Australia. J Clin Neurosci 2019;67:114-23.

3 Hirsh C. Simulation to teach the art of difficult conversations: a curriculum adaptable for all learners (FR482B). J Pain Symptom Manage 2019;57:438.

4 Rudolph JW, Raemer DB, Simon R. Establishing a safe container for learning in simulation: the role of the presimulation briefing. Simul Healthc 2014;9:339-49.

5 Eppich WJ, Mullan PC, Brett-Fleegler M, et al. "Let's talk about it": translating lessons from health care simulation to clinical event debriefings and coaching conversations. Clin Pediatr Emerg Med 2016;17:200-11.

6 Hallett M, Stone J, Preface CAVinken PJ, Bruyn GW, eds. Handbook of clinical neurology. , 2017: 139, ix-x.

7 Espay AJ, Aybek S, Carson A, et al. Current concepts in diagnosis and treatment of functional neurological disorders. JAMA Neurol 2018;75:1132.

8 Kozlowska K, Scher S. Functional somatic symptoms in children and adolescents: the Stress-System approach to assessment and treatment. London: Palgrave Macmillan. In Press, 2020.

9 Stone J, Carson A. Functional neurologic disorders. continuum: lifelong learning in neurology. , 2015: 21, 818.

10 Garcin B. Motor functional neurological disorders: an update. Rev Neurol 2018;174:203-11.

11 Carson A, Lehn AVinken PJ, Bruyn GW, eds. Epidemiology. Handbook of clinical neurology. , 2017: 139, 47-60.
12 Goldstein LH, Robinson EJ, Mellers JDC, et al. Cognitive behavioural therapy for adults with dissociative seizures (CODES): a pragmatic, multicentre, randomised controlled trial. Lancet Psychiatry 2020;7:491-505

13 LaFrance WC, Baird GL, Barry JJ, et al. Multicenter pilot treatment trial for psychogenic nonepileptic seizures: a randomized clinical trial. JAMA Psychiatry 2014;71:997-1005.

14 Stone Jet al. What should we say to patients with symptoms unexplained by disease? The "number needed to offend". BMJ 2002;325:1449-50.

15 Nielsen G, Stone J, Matthews A, et al. Physiotherapy for functional motor disorders: a consensus recommendation. J Neurol Neurosurg Psychiatry 2015;86:1113-9.

16 Gray N, Savage B, Scher S, et al. Psychologically informed physical therapy for children and adolescents with functional neurological symptoms. J Neuropsych Clin Neurosci. In Press 2020.

17 Carson A, Lehn A, Ludwig L, et al. Explaining functional disorders in the neurology clinic: a photo story. Pract Neurol 2016;16:56-61.

18 Reuber M. Dissociative (non-epileptic) seizures: tackling common challenges after the diagnosis. Pract Neurol 2019;19:332-41.

19 Adams C, Anderson J, Madva EN, et al. You've made the diagnosis of functional neurological disorder: now what? Pract Neurol 2018;18:323-30.

20 Williams B. Case based learning--a review of the literature: is there scope for this educational paradigm in prehospital education? Emerg Med J 2005;22:577-81.

21 Stone J, Hoeritzauer I, Gelauff J, et al. Functional disorders in neurology: case studies. Neurol Clin 2016;34:667-81.

22 Stone J, Sharpe M. Functional symptoms in neurology: case studies. Neurol Clin 2006;24:385-403.

23 Papadakos CT, Stringer T, Papadakos J, et al. Effectiveness of a Multiprofessional, online and simulation-based difficult conversations training program on self-perceived competence of oncology healthcare provider trainees. J Cancer Educ 2020;71:20201-9.

24 Lechner BE, Shields R, Tucker R, et al. Seeking the best training model for difficult conversations in neonatology. J Perinat Med 2016;44:461-7. 